Est Ag 47 (2012) 583-593

\title{
Algunos aspectos teológicos de mis escritos
}

LUIS RESINES

\author{
«Mal hombre y mal fraile, sí; \\ pero no fiel [=infiel], bien sabéis, Señor, \\ que no lo he sido ni tal intento nunca lo tuve».
}

(Bartolomé Carranza)

Las palabras que encabezan este artículo brotaron de los labios del Arzobispo de Toledo, una vez desencadenado su proceso que tan amargas consecuencias tuvo para su actuación, para su fama, e incluso para su propia salud. Expresadas como oración, como súplica a Dios, en la que está fuera de lugar la mentira y la falsedad, son la expresión de quien reconoce sus múltiples fallos como persona y como religioso; pero a la vez la confesión de quien siempre ha tratado de mantener - por encima de todo- la fidelidad y la lealtad para con Dios, sin vislumbrar siquiera la posibilidad de faltar a ella.

A mucha distancia del célebre arzobispo, en cuya lápida sepulcral el papa Gregorio XIII hizo grabar la inscripción en que le reconocía como «hombre ilustre por su vida, doctrina, predicación y limosnas», me permito hacer mías sus palabras y sentimientos para manifestar, en sintonía, mi voluntad de fidelidad y lealtad para con Dios, también en lo que he expresado en alguna de mis publicaciones. Mi debilidad, y mis limitaciones me llevan a participar de la suerte común de los mortales, capaces de errar, de cometer inexactitudes, o decir las cosas a medias o de manera incompleta. 
Me he parado a reconsiderar algunas afirmaciones escritas tiempo atrás y que podrían ser confusas o erróneas, o también ser mal interpretadas. Y, por el deseo de mantener la fidelidad a Dios, bien vale la pena volver a considerarlas. No importa demasiado el tiempo transcurrido desde la publicación - diez y ocho años en algún caso- si con ello las afirmaciones quedan más perfiladas, y sirven mejor para el provecho de otros en la transmisión de la fe.

1. En el libro Penitencia. La salvación del pecador (Estella, 2001), la presentación del pecado original se podría identificar con la limitación de la criatura, y por tanto no tendría consecuencias particulares sobre el hombre, simplemente porque Dios lo ha creado limitado y falible.

Acepto sin reservas la enseñanza de Trento sobre el pecado original, que señala que no se trata de un pecado imputable únicamente a Adán, y que no afectara a su descendencia; que tal pecado es transmitido por propagación y no por simple imitación. Según esta misma enseñanza, el pecado de Adán trajo como consecuencia la pérdida de la amistad con Dios, incurriendo en su ira e indignación. Tal pecado no es sólo personal, sino que se transmite a la especie humana, descendiente de él, por generación. La consecuencia es que todos los seres humanos incurrimos en el pecado, que reside en cada uno como pecado propio, así como en sus penas.

La doctrina de Trento sobre la justificación, señala que ésta tiene lugar por el renacimiento en Cristo, y de no ser así, nunca seríamos justificados. Por tanto, el hombre, inclinado al mal por el pecado, es regenerado por Cristo, quien decididamente lo inclina hacia el bien y lo justifica.

De este modo aparece clara la enseñanza precisa: que es la especie humana quien, solidaria en el pecado, es regenerada por Cristo justificador. Asumo plenamente la enseñanza de que la universalidad de la regeneración tiene como precedente la universalidad de la participación en el pecado, que afecta a todos los hombres.

2. En el mismo libro, aparece una frase que también he reconsiderado: «Para poder hablar de pecado resulta indispensable ser creyente, es decir, hacer una expresa referencia al deseo de aceptar a Dios y acatar su voluntad. Esto, por definición, no pueden hacerlo quienes no son creyentes. Por tanto, únicamente el creyente puede cometer pecados, al incumplir la voluntad de Dios, aceptada libremente».

La proposición rechazada por la doctrina de la Iglesia, de agosto de 1690 , señala que el denominado pecado filosófico «es, en verdad, pecado 
grave, pero no ofensa a Dios ni pecado mortal que deshaga la amistad con Él, ni digno de castigo eterno». Por tanto, cuando el creyente incumple la voluntad de Dios, comete pecado; cuando el no creyente lleva a cabo una acción similar, claro está que incumple la ley eterna, y que ésta es cognoscible por la conciencia recta de todo hombre; el pecado del no creyente atenta contra la ley eterna, y por consiguiente atenta contra Dios, que es de quien procede esa ley eterna. En consecuencia, quien actúa gravemente contra la ley eterna, cognoscible por la conciencia recta de todo hombre, no deja de pecar gravemente ante Dios, aunque en ese momento no piense en Él. No se puede reducir su responsabilidad a una incoherencia con el propio código ético.

La conciencia es la voz interior en el hombre, que le exige hacer el bien y evitar el mal. Es, a la vez, la capacidad de poder diferenciar el uno del otro. En la conciencia, que es testigo de la verdad, Dios habla al hombre. Es trágico que, aunque Dios hable al hombre por la conciencia, el hombre, creyente o no, pueda no hacerle caso. Hablar de «código ético» no es hablar de algo subjetivo, acomodaticio, o sin referencia a una ley eterna, a la voz de la conciencia. El hombre que no es creyente no se remite expresamente a la indicaciones formuladas por Dios en su Palabra, pero no puede en modo alguno desconocer la voz de su conciencia. Pecar, significa más que infringir alguna de las normas acordadas por los hombres. El pecado se dirige libre y conscientemente contra el amor de Dios y lo ignora. El pecado es, en definitiva, «el amor de sí hasta el desprecio de Dios»(S. Agustín), y, en caso extremo, la criatura pecadora dice: Quiero ser «como Dios» (Gn. 3, 5).

Dios sabrá cómo juzgar a cada hombre, y sabrá según su sabiduría cómo juzgar ese pecado cometido contra la ley eterna, que procede de Dios. Naturalmente, tanto el creyente, como el no creyente es responsable ante Dios. Él es el único capaz de juzgar y valorar adecuadamente a cada persona. Él sabe, aunque los hombres no seamos capaces, cómo juzgará a cada uno, y con qué criterios valorará a cada ser humano, sus hechos, sus palabras, sus intenciones y sus omisiones. No tenemos más remedio que remitir al justo juicio de Dios, que no admite excepciones: «Todos los muertos oirán su voz y saldrán de sus sepulcros. Los que hicieron el bien resucitarán para la vida eterna; pero los que hicieron el mal, resucitarán para su condenación» (Jn. 5, 29).

3. Deseo ofrecer un texto claro sobre la naturaleza del pecado grave. Asumo plenamente que según el magisterio eclesiástico actual, coincidiendo con toda la tradición, se llama "pecado mortal a aquel acto por el que 
una persona rechaza de modo consciente y libre a Dios, su ley y la alianza de amor que éste le ofrece, y prefiere convertirse a sí mismo o a alguna realidad creada y finita, a alguna cosa que está en contradicción con la voluntad divina". Tres son las notas que caracterizan la gravedad del pecado: la medida de la libertad dada y empleada, la claridad del conocimiento y la importancia de la materia [...] A diferencia de lo que sucede en los pecados graves, en los leves, la libertad o el conocimiento claro son limitados, o se trata de una materia menos importante.

Es claro que, además de las disposiciones internas de la persona, es preciso tener siempre en cuenta la existencia de unas normas objetivas de moralidad, un orden moral que es obligatorio para todos los miembros de la sociedad, y que han sido reconocidas por todos los pueblos y culturas. La historia del pueblo de Israel muestra que Dios mismo es la fuente y el fundamento último del orden moral, expresado en sus mandamientos.

4. En mi libro Sacerdotes para el pueblo de Dios (Estella, 2002), podría parecer que apenas se desarrolla la cuestión de la participación en el sacerdocio de Cristo. La apreciación de cuándo un tema está suficientemente desarrollado puede fluctuar según el criterio de uno u otro lector. Me parece que está suficientemente clara esta cuestión, con la inclusión de los textos conciliares que reproduzco a continuación, y que figuran en las p. 47-48; naturalmente asumo plenamente cuanto en ellos propone la doctrina conciliar:

«El sacerdocio común de los fieles y el sacerdocio ministerial o jerárquico se ordenan el uno para el otro, aunque cada cual participa de forma peculiar del sacerdocio de Cristo. Su diferencia es esencial no solo gradual. Porque el sacerdocio ministerial, en virtud de la sagrada potestad que posee, modela y dirige al pueblo sacerdotal, efectúa el sacrificio eucarístico ofreciéndolo a Dios en nombre de todo el pueblo: los fieles, en cambio, en virtud del sacerdocio real, participan en la oblación de la eucaristía, en la oración y acción de gracias, con el testimonio de una vida santa, con la abnegación y caridad operante» (Lumen gentium, 10).

«El Señor Jesús "a quien el Padre santificó y envió al mundo" (Jn. 10,36), hizo partícipe a todo su Cuerpo Místico de la unción del Espíritu con que Él está ungido: pues en Él todos los fieles se constituyen en sacerdocio santo y real, ofrecen a Dios, por medio de Jesucristo, sacrificios espirituales y anuncian el poder de quien los llamó de las tinieblas a su luz admirable (...) El mismo Señor constituyó a algunos ministros, que 
ostentando la potestad sagrada en la sociedad de los fieles, tuvieran el poder sagrado del Orden para ofrecer el sacrificio y perdonar los pecados y desempeñaran públicamente, en nombre de Cristo, la función sacerdotal en favor de los hombres para que los fieles se fundieran en un solo cuerpo, en que "no todos los miembros tienen la misma función" (Rom. 12,4)» (Presbyterorum ordinis, 2).

En estos textos aparece con claridad absoluta que el sacerdote actúa en virtud de la sagrada potestad que posee, con ella modela y dirige al pueblo sacerdotal, y desempeña el poder sagrado del orden para ofrecer el sacrificio y perdonar los pecados, en nombre de Cristo. Y no tengo duda alguna en cuanto afirma y enseña el concilio, que asumo y hago mío.

5. En el mismo libro, podría dar la sensación de una presentación insuficiente si los elementos perennes de la identidad del sacerdote se redujeran sólo a «la fidelidad a Jesús, la vivencia de la fe, el servicio a sus hermanos cristianos, a la comunidad» (p. 112).

Este tema, que he desarrollado en las p. 111-112, es una suposición de cómo será el sacerdote del futuro: habrá cosas que cambiarán, como han cambiado otras del pasado, y habrá otras que permanecerán, como las señaladas. Entre esos elementos perennes de la identidad sacerdotal continuarán estando presentes los que constituyen el ministerio sacerdotal: que es el mismo Señor quien elige a algunos de entre su pueblo santo, a los que confiere la potestad sagrada del Orden para que, en su nombre, desempeñen la función sacerdotal en beneficio de sus hermanos, difundiendo la palabra de Dios, ejerciendo la función ministerial litúrgica y dirigiendo al pueblo sacerdotal. Estos elementos constitutivos del ministerio sacerdotal podrán y deberán ser acompañados de los otros elementos señalados, que en modo alguno excluyen los que acabo de indicar, sino que precisamente los presuponen y se derivan de ellos. En modo alguno se ha de reducir el ministerio sacerdotal a una simple actitud de servicio.

Igualmente, podría haber una apreciación que redujera mi reflexión a señalar que «lo único que pareciera esperarse de él (el sacerdote) es que sea una persona "que viva su fe, que sepa ayudar a sus hermanos a vivirla y que se muestre ejemplar a la hora de decir lo que hay que hacer y a la hora de hacerlo ella misma"» (p. 65). El contexto de esta frase señala que existe una larguísima lista de sínodos y concilios que abordan la cuestión de la vida y honestidad de los sacerdotes: en esos apartados señalan los múltiples defectos y fallos de cada lugar y de cada época. Y cuando corrigen semejantes 
abusos, los sínodos y concilios referidos pretenden acercarse al ideal de sacerdote, de obispo y de diácono, que puede estar descrito con las frases examinadas. Describir en grandes líneas cuál puede ser una conducta ideal es bien distinto de tratar de hacer una definición de lo que es propio y específico del sacerdote. Para ello, ya he empleado los textos conciliares, que lo señalan con justeza.

6. En el tema del celibato sacerdotal, he presentado que éste se «mantiene exclusivamente por motivos de tipo funcional y contexto histórico, sin hacer referencia a las motivaciones teológicas». En el contexto de la p. 140, que se cita, aparece una explicación comparada entre las diversas disciplinas que son mantenidas por diversas comunidades cristianas (católicos de rito occidental y de rito oriental, ortodoxos, anglicanos y confesiones protestantes). No constituye inexactitud, parcialidad u ocultamiento presentar así las cosas, y hacer referencia expresa a la «existencia de una ley eclesiástica» (p. 103), que «obedece a disposiciones de la Iglesia y no de Jesús». Que la ley eclesiástica esté apoyada en motivaciones teológicas, es lógico, pues toda ley lógica se debe sustentar en razones. Razones teológicas son que el mismo Cristo recomendó la perfecta castidad por el Reino de los cielos; que el celibato posibilita en la misión del sacerdote una mayor dedicación para el servicio; que trasluce con mayor claridad el misterio de la vinculación de la Iglesia con Cristo, como su único esposo a quien sigue; que la entrega a Cristo con un corazón indiviso testimonia la confianza en la gracia de Dios. Estas razones teológicas sustentan la aceptación del don del celibato sacerdotal en la Iglesia.

No presentar estas razones en este libro no equivale a negarlas o desconocerlas.

7. He calificado «la declaración de Juan Pablo II sobre la imposibilidad del acceso de las mujeres al sacerdocio de "gesto autoritario", que no habría cerrado el debate teológico».

El adjetivo «autoritario» tiene un doble sentido, complementario: el de ejercer la autoridad, y el de imponer la autoridad. Juan Pablo II ha ejercido y ha impuesto su autoridad, al señalar como dictamen definitivo que la Iglesia no tiene en modo alguno la facultad de conferir la ordenación sacerdotal a las mujeres. Acepto firme y cordialmente esta decisión, y la comparto y compartiré. No es una cuestión dogmáticamente definida, pero sí es un dictamen definitivo. Y como tal dictamen con carácter definitivo, procede 
reconocer que las mujeres quedan excluidas de la ordenación sacerdotal. Pero esto no supone que las mujeres no estén llamadas al apostolado, con una participación activa y responsable en la vida de la Iglesia. Es necesario que la Iglesia reconozca todos los dones de las mujeres y de los hombres, para que su misión se haga más eficaz.

A la luz de estas consideraciones es como se ha de entender mi afirmación de que «no es una cuestión cerrada, porque los términos de su declaración -teológicamente hablando- no dejan zanjado el asunto», que queda así rectificada.

8. En dos artículos míos, que tienen como elemento común considerar diversos aspectos del Catecismo de la Iglesia Católica: "Análisis del Catecismo de la Iglesia Católica" (Estudio Agustiniano, 1993) y "El Catecismo de la Iglesia Católica" (Catequética, 1993), aparecen algunas afirmaciones que, para ser correctamente entendidas, han de ser matizadas y situadas en su propio contexto.

La primera afirmación que podría ser mal interpretada sería la de suponer que considero que el Catecismo de la Iglesia Catócila es un texto de referencia sin algún "carácter normativo" (Análisis, p. 196), no obstante el Romano Pontífice enseñe lo contrario en la constitución Fidei Depositum n. 4. En cambio, el artículo, en la p. 196 dice en su contexto:

«El propio Juan Pablo II hace además una afirmación citando anteriores palabras suyas, según las cuales, "el Vaticano II ha sido siempre... el punto constante de referencia de toda mi acción pastoral" (n. 1, pg. 8). Es perfectamente normal que pueda haber más de un punto o texto de referencia para guiar la actuación personal de cualquier cristiano. Pero no es éste el sentido de las afirmaciones, sino que lo que parece establecerse es un paralelismo entre el Concilio Vaticano II y el Catecismo, del que se afirma rotundamente que es "texto de referencia para una catequesis renovada". La más consolidada tradición eclesial ha distinguido entre las solemnes afirmaciones magistrales de un concilio ecuménico, y las afirmaciones de un catecismo, que no es documento conciliar».

Asimismo, en el Catecismo se deben distinguir dos niveles doctrinales: el relativo a la sustancia de la fe; y el que se refiere a otras explicaciones, necesarias en un texto catequético, pero ciertamente secundarias. Naturalmente en las afirmaciones doctrinales que contemplan y transmiten la sustancia de la fe, el Catecismo tiene un carácter de texto de referencia, como 
no podía ser de otra forma. Así lo he afirmado como consta en el párrafo anterior, y así lo mantengo y lo mantendré. En cuanto a las explicaciones secundarias, que no afectan a la sustancia misma de la fe, cabe la valoración sobre su oportunidad, su conexión con los elementos nucleares, su importancia. Un catecismo no es un símbolo de la fe, y necesariamente ha de poner en juego cuadros explicativos instrumentales, y por tanto no de valor dogmático.

Nunca he afirmado que «el Catecismo de la Iglesia Católica es un texto de referencia sin algún "carácter normativo"». Muy al contrario, mi afirmación es que es «texto de referencia... de los grandes y substanciales quicios de la fe cristiana»; pero en «afirmaciones secundarias... de ninguna manera se puede compartir el carácter normativo de que se quiere dotar al texto». Afirmar esto es tener en cuenta la enseñanza de Evangelii nuntiandi, 25:

«En el mensaje que anuncia la Iglesia hay ciertamente muchos elementos secundarios, cuya presentación depende en gran parte de los cambios de circunstancias. Pero hay un contenido esencial, una sustancia viva que no se puede modificar ni pasar por alto sin desnaturalizar gravemente la evangelización misma».

La segunda afirmación, que podría suscitar interpretaciones no deseadas, es mi "voluntad decidida de ejercer el derecho a la crítica" (Análisis, p. 225)». El contexto en que aparece mi afirmación es el siguiente:

«Manifiesto a los cuatro vientos mi voluntad decidida de ejercer el derecho a la crítica (para lo positivo y para lo negativo) desde dentro de la propia Iglesia, en plena comunión eclesial, queriendo y fomentando que haya cada vez más cristianos conscientes y responsables, que haya una presentación de la fe que se ajuste más y más a los dictados del evangelio de Jesús de Nazaret y a necesidades y aspiraciones de los hombres. Y lamento y lamentaré todas las voces autoritarias que pretendan reducir la crítica al silencio, so capa de cerrar filas y fomentar la unión. ¿Para cuándo y para dónde, si no, hay que dejar la «libertad de los hijos de Dios» (Rm. 8, 21)? ¿Cuál es el terreno adecuado para examinar un Catecismo, si las conclusiones del examen han de permanecer en las catacumbas?» (Análisis, p. 225)».

Ejercer el derecho a la crítica no constituye ningún acto de insumisión o desobediencia, sino de comunión eclesial, acorde con lo que enseña el Vaticano II: 
«Los laicos, como todos los fieles cristianos, tienen el derecho de recibir con abundancia, de los sagrados pastores, de entre los bienes espirituales de la Iglesia, ante todo, los auxilios de la Palabra de Dios y de los sacramentos; y han de hacerles saber, con aquella libertad y confianza digna de Dios y de los hermanos en Cristo, sus necesidades y sus deseos.

En la medida de los conocimientos, de la competencia y del prestigio que poseen, tienen el derecho y, en algún caso, la obligación de manifestar su parecer sobre aquellas cosas que dicen relación al bien de la Iglesia.

Hágase esto, si las circunstancias lo requieren, mediante instituciones establecidas al efecto por la Iglesia, y siempre con veracidad, fortaleza y prudencia, con reverencia y caridad hacia aquellos que, por razón de su oficio sagrado, personifican a Cristo» (Lumen gentium, 37).

La tercera afirmación que requiere alguna matización sobre el Catecismo de la Iglesia Católica es que éste es "un instrumento a utilizar entre otros posibles, pero ciertamente no el mejor, ni tampoco el peor" (Análisis, p. 265).

En este punto concreto, como conclusión del artículo en que aparece mi aserto, el contexto de la afirmación que presento es ésta:

«Creo, en definitiva, que el Catecismo es un instrumento (Fidei depositum, 4) a utilizar entre otros posibles, pero ciertamente no el mejor, ni tampoco el peor; creo que es un servicio (Fidei depositum, 4; también, $\mathrm{n}$. 1.075) que puede reportar alguna utilidad. Sin necesidad de echar las campanas al vuelo, conscientes de las limitaciones y los logros que comporta, los dispuestos a hacer un esfuerzo de lectura y estudio, pueden utilizarlo como una orientación, entre otras, para conocer y exponer la fe» (Análisis, p. 265).

Esta conclusión es el resultado de un estudio en profundidad, analizando los aciertos y las limitaciones, las cualidades y los defectos del Catecismo. Constituye «la obligación de manifestar su parecer sobre aquellas cosas que dicen relación al bien de la Iglesia, en la medida de los conocimientos, de la competencia y del prestigio que poseen». Siento que esto se pueda interpretar como un acto adverso, cuando es precisamente todo lo contrario.

9. También entiendo que es preciso reconsiderar otra afirmación mía, a fin de que no sea mal entendida, como si se tratara de una libertad que me tomara por mi cuenta para aceptar o no afirmaciones del Catecismo de la 
Iglesia Católica. Lo que he afirmado es: "ejerzo, con apasionado deber y sentido eclesiales, mi derecho a criticar los contenidos del Catecismo de la Iglesia Católica"»(Análisis, p. 226). El límite al ejercicio del derecho al disenso serían los dogmas de fe que en él se recogen, mientras que "es lícito disentir de algunos planteamientos que aparecen en las páginas del Catecismo que no son cuestiones cerradas, sino abiertas y opinables (El Catecismo, 127).

Entiendo que el Catecismo es un instrumento más, con sus aciertos y sus limitaciones. En su fondo explicativo, en la transmisión de la fe de la Iglesia, constituye un testimonio normativo de esa misma fe de la Iglesia, como presenta Juan Pablo II en Fidei depositum, 4. En los aspectos secundarios, en las mediaciones con que se expone la verdad dogmática, en aspectos disciplinares, o en aplicaciones prácticas para la vida cristiana, el carácter normativo cede en importancia.

10. Otras observaciones que requieren mi adhesión de fe:

1) Respecto a la imposibilidad de la ordenación sacerdotal de las mujeres. Ya lo he hecho unos párrafos más arriba.

2) Respecto a la afirmación de que cualquier acto conyugal debe permanecer abierto a la transmisión de la vida (Humanae vitae, 11): expreso mi adhesión de fe a este principio. Igualmente expreso mi adhesión de fe a la afirmación de Humanae vitae, 11, cuando señala que los actos conyugales «no cesan de ser legítimos si, por causas independientes de la voluntad de los cónyuges, se prevén infecundos, porque continúan ordenados a expresar y consolidar su unión». Igualmente expreso mi adhesión de fe a Humanae vitae, 16, según el cual «la Iglesia enseña que entonces es lícito tener en cuenta los ritmos naturales inmanentes a las funciones generadoras para usar el matrimonio sólo en los períodos infecundos y así regular la natalidad sin ofender los principios morales que acabamos de recordar».

3) respecto a la prohibición de disolver el pacto matrimonial y contraer nuevas nupcias: expreso mi adhesión de fe a este principio, sin que obste el texto de Mt. 19, 9: "Salvo en el caso de fornicación". En este punto me he limitado a constatar la existencia de una fuerte corriente de opinión en la Iglesia, que ha tratado de entender y aplicar correctamente el texto evangélico. Dejar constancia de ese hecho histórico no quiere decir que haya que participar de tal criterio. Como indico, «no se trata de que esta 
excepción deje un portillo abierto a la exigencia evangélica, como si se tratara de una trampa de la ley. Se trata más bien de comprobar la dificultad de una adecuada interpretación» (Análisis, 257).

11. Respecto a los grados de asentimiento del fiel, conozco y acepto tal graduación (expresada en Donum veritatis, 14-17), y entiendo que en aquellas cuestiones en las que el Magisterio eclesial no tiene intención de poner un acto definitivo, dado que, por eso mismo, y según la misma enseñanza de éste, esas cuestiones "pueden ser siempre profundizadas". Por eso precisamente deben ser objeto de valoración, y valoración crítica de parte del teólogo, a fin de que éste pueda cumplir su papel en la Iglesia, tal como ha sido abundantemente repetido por el respectivo magisterio de Juan Pablo II. Tal valoración crítica que permitirá profundizar y mejorar dicha enseñanza, ha de hacerse, sin duda, con obsequio religioso hacia la enseñanza del Magisterio.

Aprovecho la ocasión para manifestar justamente ese talante, desde el cual he querido hacer, como otros muchos teólogos, una valoración de algunos elementos del Catecismo en su condición de instrumento y referencia para la presentación de la fe, pero no en la proclamación de la verdad dogmática de la fe eclesial.

Deseo así dejar clara mi postura frente a posibles interpretaciones, a fin de que sea adecuadamente entendida, y, si fuera preciso, rectificar los puntos señalados. 
